\title{
Política pública para a construção da escola popular: a rede pública municipal pelo direito de ensinar e de aprender
}

\author{
Gercina Santana Novais ${ }^{1}$, Silma Carmo Nunes²
}

\begin{abstract}
Resumo
Neste texto abordamos a experiência da construção da política educacional desenvolvida pela Secretaria Municipal de Educação de Uberlândia, Minas Gerais, tendo como fonte dados oriundos de uma pesquisa desenvolvida no período de 2014 a 2016, fundada na metodologia da pesquisa-ação. Os documentos registros das rodas de conversa e dos mini fóruns - produzidos pela pesquisa-ação, foram disponibilizados para a realização de análise documental, com enfoque qualitativo. Foram analisados registros das Rodas de Conversa e dos Mini Fóruns realizados nas unidades escolares do ensino fundamental, comunicados, memorial, levantamento sobre a realidade da educação em Uberlândia e Lei Municipal n 11.444/2013. Os resultados da análise evidenciaram a importância da referida lei, que fundamentou a construção da política pública municipal de educação cuja finalidade era garantir às classes populares educação pública, gratuita, popular, de qualidade referenciada socialmente. Mostraram a centralidade da gestão democrática no fomento da escola pública popular, da participação dos/as profissionais e demais interessados/as em educação pública e gratuita, nos espaços coletivos de discussão e elaboração de ações pedagógicas. E, também, das proposições sobre formação com os/as profissionais da educação como políticas públicas educacionais. Revelaram, ainda, a aproximação dos valores e das diretrizes, presentes nos documentos analisados, com as proposições do campo da educação popular.
\end{abstract}

\section{Palavras-chave}

Escola Popular. Rede. Pesquisa-Ação. Rodas de Conversa. Formação Profissional.

1. Doutora em Educação pela Universidade de São Paulo, Brasil; professora do Programa de Mestrado em Educação da Universidade de Uberaba, Minas Gerais, Brasil. E-mail: gercinanovais@yahoo.com.br.

2. Doutora em Educação pela Universidade Estadual de Campinas, São Paulo, Brasil; diretora acadêmica da Faculdade de Educação e Estudos Sociais de Uberlândia, Faculdade Presidente Antonio Carlos e membro do Grupo de Estudos e Pesquisa Sobre Ensino de Geografia da Faculdade de Educação da Universidade Federal de Uberlândia, Minas Gerais, Brasil. E-mail: leosilma@terra.com.br. 


\title{
Public policy for the construction of the popular school: a public municipal network for the right to teach and to learn
}

\author{
Gercina Santana Novais*, Silma Carmo Nunes ${ }^{* *}$
}

\begin{abstract}
In this text we discussed about the experience of the construction of educational policy developed by the Municipal Secretary of education of Uberlândia, State of Minas Gerais, with data from source of a research developed in the period from 2014 to 2016, that was founded on the methodology the action research. The documents - records of the conversation circles and mini forums - produced by action research, were made available for the realization of documentary analysis, with qualitative approach. We analyzed records of the conversation circles and mini forums held in the elementary school, announcements, memorial, survey on the reality of education in Uberlandia and municipal law 11.444/2013. The results of the analysis showed the importance of this law, which was based on the construction of municipal public education policy which purpose was to ensure that popular classes receive free, popular, and public education with socially referenced quality. They showed the centrality of democratic management in promoting popular public schools, the participation of professionals and others parties interested in free public education, in collective spaces of discussion and elaboration of pedagogical actions. And, also, about propositions regarding training with the education professionals as public educational policies. They revealed the approximation of values and guidelines present in the documents analyzed, with the propositions of the field of popular education.
\end{abstract}

\section{Keywords}

Popular School. Network. Action Research. Wheels of Conversation. Vocational Training.

* PhD in Education, University of São Paulo, State of São Paulo, Brazil; professor of the Master's Program in Education at the University of Uberaba, State of Minas Gerais, Brazil. E-mail: gercinanovais@yahoo.com.br.

** PhD in Education, State University of Campinas, State of São Paulo, Brazil; academic director of the Faculty of Education and Social Studies of Uberlândia, Faculty President Antonio Carlos; member of the Group of Studies and Research on Teaching of Geography of the Faculty of Education of the Federal University of Uberlândia, State of Minas Gerais, Brazil. E-mail: leosilma@terra.com.br. 


\section{Introdução}

[...] o diálogo é uma exigência existencial. E, se ele é o encontro em que se solidariza o refletir e o agir de seus sujeitos endereçados ao mundo a ser transformado e humanizado, [...]. É um ato de criação (FREIRE, 1987, p. 51).

A construção da escola pública, como espaço crivado de teorias e práticas que favorecem e legitimam a desigualdade de oportunidade, sempre necessitou de dispositivos de violência: ausência de diálogo; invisibilidade da condição de estudo oferecida para parcela significativa da população; responsabilidade por resultados educacionais atribuída ao/à estudante ou ao/à professor/a; definição da educação como serviço e não como direito humano; desvalorização de saberes de determinados grupos sociais. Esses dispositivos colaboram para a permanência de monólogos sobre conteúdos curriculares e políticas públicas de educação elaboradas sem escutar as demandas da comunidade escolar e demais interessados/ as em educação pública gratuita.

Todavia, esse longo processo de condição desigual de escolarização não tem ocorrido sem resistência. Os grupos que praticam a resistência anunciam teorias e práticas orientadas pelo desejo de transformar realidades escolares. Argumentam a favor da importância do diálogo no processo de construção da escola pública popular, estruturada a partir das demandas e interesses dasclasses popularese docompromisso com processos de humanização (FREIRE, 1987). Para fortalecer a possibilidade de criação da escola pública popular são fundamentais as reflexões acerca das experiências educacionais que ocorrem em oposição ao proposto por aqueles/as que precisam da continuidade do pensamento colonizador.

Nessa perspectiva, este texto retoma e analisa uma parcela dos dados oriundos de uma pesquisa-ação ${ }^{3}$ (THIOLLENT, 2009), desenvolvida no período de 2014 a 2016, na Rede Pública de Ensino do Município de Uberlândia-MG, utilizando-se das rodas de conversa ${ }^{4}$ e dos mini fóruns como espaços de discussão dos problemas que afetam processos de ensino e aprendizagem e de elaboração, desenvolvimento e avaliação de ações coletivas, visando superá-los. Essa pesquisa-ação almejava formular e desenvolver, coletivamente, políticas públicas ${ }^{5}$ de educação democrática, popular, de qualidade social e gestada em rede. E, ainda, elaborar, desenvolver e avaliar, coletivamente, as ações que materializassem essa política. O fato provocador da referida pesquisa decorreu da necessidade de intervir, coletivamente, nos resultados do levantamento

3. O projeto de pesquisa-ação utilizou-se dos seguintes procedimentos: a) análise de documentos (registro dos dados sobre cada escola, com base nos documentos: Programa de Apoio à Gestão da Escola (PDDE), relatórios da inspeção, relatórios de resultado de avaliações educacionais, blog das unidades escolares, dentre outros); b) escuta ativa com a unidade gestora e todos/as os/as profissionais da educação com vistas a desenvolver estudo de caso, envolvendo resultados educacionais e história da unidade escolar; c) Rodas de Conversa em cada unidade escolar do ensino fundamental, visando repensar coletivamente os resultados educacionais e as práticas curriculares, o planejamento, os processos de avaliação e gestão da escola a fim de promover as intervenções necessárias para a melhoria da qualidade social da educação.

4. As rodas de conversa realizadas pelas escolas partiam de um tema a ser problematizado. Para isso, as unidades escolares deveriam elencar, conforme as suas prioridades, as demandas a serem discutidas e se organizarem para aquele momento. As rodas de conversa adotadas pela rede municipal de ensino documentaram suas ações por meio dos registros escritos e fotográficos das atividades desenvolvidas e com as análises sobre os documentos. 5. O entendimento de política pública expressa na afirmativa o que o governo escolhe fazer ou não fazer (DYE, 1984) foi incorporado na análise da política pública de educação. 
preliminar sobre a realidade da educação pública, realizado no primeiro semestre do ano de 2013, na rede municipal de ensino do município de Uberlândia-MG. As fontes documentais para levantamento dos problemas identificados nessa rede foram os relatórios dos/ as inspetores/as escolares produzidos durante as visitas rotineiras às unidades escolares, além dos relatórios dos setores da Secretaria Municipal de Educação de Uberlândia (SME), como: coordenações da educação infantil e do ensino fundamental, setor de apoio, responsável por cuidar da infraestrutura, ou seja, reformas e construções nas unidades escolares; caixa escolar; Programa Municipal de Alimentação Escolar (PMAE), marcenaria, responsável pela reforma e produção de mobiliário escolar; setor de transportes, responsável pelo traslado de alunos/as, professores/as e funcionários/as das escolas localizadas na zona rural e distrital do município; e outros. Decorreu, também, da urgência de refletir, coletivamente, sobre os significados dessa realidade para os processos de escolarização das classes populares ${ }^{6}$ e de buscar a superação das "situações-limites" (FREIRE, 1987) identificadas: gestão autoritária, hierarquizada e piramidal; parcela significativa de aluno/as com resultados insatisfatórios em Língua Portuguesa, Matemática, História, Ciências e Geografia; Plano de Cargos e Carreira e Projetos Políticos Pedagógico das unidades escolares sem revisão há mais de 10 anos; 90\% das escolas necessitando de reformas e manutenção em instalações físicas e elétricas, urgentes; insuficiência de vagas no ensino fundamental, na educação de jovens e adultos e na educação infantil; e, queixas sobre o afastamento da formação continuada da realidade das unidades escolares, dentre outras situações-limites. Como argumenta Freire (1987, p. 51), acerca das "situações-limites",

No momento em que os homens as apreendem como freios, em que elas se configuram como obstáculos à sua libertação, se transformam em "percebidos destacados" em sua "visão de fundo". Revelam-se assim, como realmente são: dimensões concretas e históricas de uma dada realidade. Dimensões desafiadoras dos homens, que incidem sobre elas através de ações que Vieira Pinto chama de "atos limites" - aqueles que se dirigem à superação e à negação do dado, em lugar de implicarem na sua aceitação dócil e passiva.

Assim, o processo de reflexão-açãoreflexão sobre as "situações-limites, desenvolvida durante a realização da pesquisa-ação, contemplou a análise crítica das proposições e experiências de escolarização das classes populares. Contemplou o reconhecimento de que a política pública de educação deveria ser ancorada no fortalecimento da "autonomia do ser do educando" (FREIRE, 1996, p. 59). Ancorada, ainda, na disponibilidade para o diálogo e reflexão crítica sobre a prática, as ações desenvolvidas por governos do campo democrático $^{7}$ e as proposições anunciadas por diferentes movimentos ou instituições mereceram atenção especial. Essas ações e proposições, fundadas na democratização do acesso ao ensino e à aprendizagem, com permanência e conclusão dos estudos com qualidade social, majoritariamente,

6. Concordamos com Wanderley (2010, p. 41), quando esclarece sobre classes populares: "Uma maioria de oprimidos, marginalizados, discriminados, e, mais proximamente excluídos. A configuração é ampla, e inclui os membros contidos nos dois ângulos antes indicados: os privados dos bens materiais necessários a uma vida digna; aqueles cujas opressões são dadas pela discriminação racial, étnica e sexual; os migrantes estrangeiros; os marginalizados (desempregados, subempregados, trabalhadores da economia submersa, os miseráveis englobando mendigos, menores abandonados, prostitutas etc.); os explorados (operários e lavradores); a franja inferior do setor de serviços (pequenos funcionários, professores primários, pequenos comerciantes etc.)".

7. A título de ilustração, citamos as experiências desenvolvidas por Luiza Erundina de Sousa, na Prefeitura de São Paulo (1989-1992) e por Patrus Ananias de Sousa, na Prefeitura de Belo Horizonte (1993-1996). 
permaneciam ausentes da discussão sobre políticas públicas de educação no município em questão. As discussões foram fundamentadas, especialmente, nas formulações teóricas e metodológicas da educação popular ${ }^{8}$ (FREIRE, 1987; 1996) e na teoria histórico-cultural sobre a importância da linguagem e do outro nos processos de desenvolvimento e aprendizagem (VYGOTSKY, 1991).

Os documentos denominados Registros das Rodas de Conversa e dos Mini Fóruns ${ }^{9}$, produzidos pela pesquisa-ação, foram disponibilizados para a realização de análise documental (CELLAR, 2008), com enfoque qualitativo, cujos resultados são apresentados neste texto. Assim, o conjunto de documentos analisados contemplou:

a. Registros das rodas de conversa e dos mini fóruns, oriundos da pesquisa-ação mencionada anteriormente, realizadas nas 53 escolas municipais de ensino fundamental.

b. Comunicados da Secretaria Municipal de Educação/Centro Municipal de Estudos e Projetos Educacionais Julieta Diniz (CEMEPE), relativos à formação continuada, à gestão em rede e aos espaços de discussão coletiva.

c. CEMEPE: Memorial 2013-2016.

d. Registro dos resultados do levantamento sobre a realidade da educação em Uberlândia realizado no primeiro semestre de 2013. e. Lei Municipal no 11.444/2013 que estabelece a Rede Pública Municipal pelo Direito de Ensinar e de Aprender.

A partir das formulações sobre a gestão da educação e dos conhecimentos contidos nos documentos analisados, as questões orientadoras da referida análise foram: Qual proposição de gestão pública de educação revelam os documentos e seus vínculos com a educação popular? Como a formação com o/a profissional da educação foi constituída?

Para compor respostas para essas questões, buscamos o contexto de produção dos documentos, os conceitos e proposições que constavam nos referidos documentos sobre gestão pública da educação, formação com os/as profissionais da educação e seus vínculos com a educação popular. Para tanto, foram realizadas as seguintes etapas: a) leitura preliminar; b) leitura e definição dos eixos temáticos; c) leitura orientada pelos eixos temáticos (concepção de gestão pública e de educação popular; desenho da formação docente, gestão pública e educação popular); d) entrecruzamentos dos resultados das análises dos documentos e elaboração de relatórios.

\section{O contexto da produção dos documentos e as escolhas teóricas}

Durante a discussão preliminar do registro dos resultados sobre a realidade educacional do município de Uberlândia, tendo em vista a qualidade social da educação pública, revisitamos definições e usos da expressão qualidade da educação e os significados do acréscimo do termo social, porque a expressão qualidade da educação é polissêmica. O

8. Consta no Marco de Referência da Educação Popular (2013, p. 29): "A Educação Popular anuncia que entre as situações-limites, geradoras de violência, e os inéditos viáveis, expressão de Paulo Freire, que significa as possibilidades de superação das situações-limites, encontra-se a educação como ação reflexiva e como prática cultural comprometida com a luta em direção ao 'ser mais', dimensão ontológica do ser humano".

9. Os registros foram elaborados por participantes das rodas de conversa e dos mini fóruns escolhidos/as para realizar tal tarefa. 
exame dos usos recorrentes da expressão revela escolhas sobre concepções e finalidades da educação e das instituições escolares, anúncio do grupo que deve cumprir apenas algumas das etapas de escolarização e quais componentes curriculares e conteúdos devem compor os currículos escolares.

Revela, ainda, a relação entre alunos/as, oportunidades de estudos e oferecimento de postos de trabalho valorizados no mercado de trabalho, dentre outras questões. Desse modo, é fundamental sublinharmos que "nas políticas sociais do país, ocorre uma transposição direta do conceito de qualidade própria dos negócios comerciais para o campo dos direitos sociais e, nestes, a educação pública" (SILVA, 2009, p. 219). Mas, ao nosso ver, tendo em vista a educação com as classes populares, a concepção de qualidade da educação e o acréscimo do termo social adotados são compreendidos de modo adequado recorrendo ao pensamento de Gadotti (2010, p. 7):

Qualidade significa melhorar a vida das pessoas, de todas as pessoas. Na educação a qualidade está ligada diretamente ao bem viver de todas as nossas comunidades, a partir da comunidade escolar. A qualidade na educação não pode ser boa se a qualidade do professor, do aluno, da comunidade é ruim.

Essa concepção de qualidade da educação, fundada nas formulações de Gadotti (2010) e de Freire $(1987$; 1996), embasa a concepção político/pedagógica da construção e elaboração do projeto educacional para o município de
Uberlândia-MG. Tal projeto denominou-se Rede Pública Municipal Pelo Direito de Ensinar e de Aprender, oficializado pela Lei Municipal no $11.444 / 2013^{10}$ sancionada pelo prefeito municipal, gestão 2013/2016, e publicada no Diário Oficial do Município (DOM), em 24de julho de 2013.

A referida lei foi elaborada e aprovada em uma conjuntura local que contava com uma administração cujo prefeito é professor da rede pública estadual de Minas Gerais, negro, ex-deputado federal, e que se elegeu por meio de uma aliança com vários partidos políticos ${ }^{11}$. E, uma das propostas de seu governo era transformar Uberlândia em Cidade Educadora, fundada em uma gestão pública que favorecesse a inclusão social.

Conforme mostrou a análise documental acima mencionada, o texto da referida lei é destinado àquelas instituições e pessoas interessadas em desenvolver educação pública de qualidade social e em compor redes de colaboração para alcançar tal propósito. Toma como conceitos-chave do texto, "escola pública" como instituição gratuita, democrática, popular e de qualidade social; "gestão em rede"; e "participação". São citados/as como participantes da construção desse tipo de escola, representantes de organizações ${ }^{12}$, entidades ou instituições da sociedade civil, as instituições do Estado e os grupos de convivência dos/as alunos/ as. A argumentação para sustentar a criação da Rede ancorou-se na defesa da necessidade de garantir escola pública, gratuita, democrática e de qualidade social, no reconhecimento da

10. A Lei $n^{\circ} 11.444 / 2013$ criou a Rede Pública Municipal pelo Direito de Ensinar e de Aprender composta por representantes do Poder Executivo Municipal, sociedade civil, entidades e organizações sociais e pelos cinco Polos. Dentre os objetivos dessa Lei, citamos: “[...] V - favorecer a construção da cultura de cooperação, acompanhamento, avaliação das ações relativas ao enfrentamento das múltiplas causas do baixo rendimento e da evasão escolar; VI - ampliar possibilidades de construção coletiva de programas e serviços que atuem no enfrentamento das dificuldades de escolarização e na melhoria do desenvolvimento educacional; [...]; XII fomentar a atuação conjunta para resolver problemas educacionais de atuação das instituições [...]; XIII - garantir um ambiente propício ao direito de ensinar e aprender [...]". (Prefeitura Municipal de Uberlândia, 2013).

11. Coligação Nossa Gente Unida por Uberlândia (PRB/PDT/PT/PMDB/PSL/PPS/PSDC/PRTB/PSB/PV/PC do B).

12. A título de ilustração: Grêmios Estudantis e Associações de Moradores. 
importância do financiamento público e da participação de diferentes instituições, que desenvolvessem atividades relacionadas à educação, no sentido da resolução de problemas identificados na educação escolar.

Consta da Lei no 11.444/2013 que a responsabilidade pelo financiamento das ações da Rede Pública Municipal pelo Direito de Ensinar e de Aprender é de responsabilidade do poder público. E os recursos financeiros para sua implantação e funcionamento são provenientes das Funcionais Programáticas ${ }^{13}$, conforme "Capítulo VII, Das disposições finais, Art. 12". Outro argumento para justificar a criação da referida lei decorria da recusa do tipo de gestão pública caracterizada pela hierarquização, fragmentação, ausência de participação e seus significados para/nos processos de escolarização da maioria da população. Em relação aos processos de comunicação e gestão pública, constam como objetivos da Lei:

XI - criar mecanismos de comunicação permanente entre os membros da Rede e um fórum de discussão sobre a escolarização de cada aluno, sendo o cronograma e as pautas das reuniões do referido fórum definidos coletivamente pelos representantes das instituições membros da Rede;

XII - fomentar a atuação conjunta para resolver problemas educacionais e colaborar para a mudança de lógica e formas predominantes de atuação das instituições do Estado. (UBERLÂNDIA, 2013, grifos nossos).

Quanto à organização e disponibilização de serviços da Rede Pública pelo Direito de Ensinar e de Aprender, constam no capítulo V:

Art. 6을 A Rede Pública Municipal pelo Direito de Ensinar e de Aprender será organizada tendo como base os diferentes setores territoriais do Município de Uberlândia e as instituições que desenvolvam atividades relacionadas à educação presentes em cada um desses setores.

$[\ldots]$

$\S 4$ o O conjunto de serviços disponibilizados pela Rede Pública Municipal pelo Direito de Ensinar e de Aprender será disponibilizado por instituições públicas, mas o seu funcionamento necessita da colaboração e participação da sociedade civil organizada e dos membros dos grupos de convivência familiar dos alunos. (UBERLÂNDIA, 2013, grifos nossos).

É possível, ao trazer elementos do contexto de produção e conceitos-chave presentes no texto da lei, evidenciar críticas e proposições sobre gestão pública da educação. Isso, em uma conjuntura na qual a oposição às forças conservadoras (defesa da redução do papel do estado na materialização dos direitos sociais e da participação popular na definição de prioridades do governo) vence as eleições (municipal e federal), mas realiza aliança com membros das forças conservadoras. A Lei no 11.444/2013 é aprovada na Câmara Municipal, no início do Governo Municipal Gestão 2013/2016, momento em que a maioria dos/as vereadores/ as ainda permanecia na base do governo.

O texto da Lei, a partir do reconhecimento do direito à educação qualificada socialmente, livre de preconceitos e discriminações e vinculado à conquista da cidadania ativa propôs o enfrentamento das múltiplas causas do "baixo rendimento" e da "evasão escolar". E, também, a gestão da educação em rede, fomentando a participação de instituições e pessoas no processo de leitura e discussão da realidade educacional dos diferentes espaços da cidade de Uberlândia.

A ideia de Rede pelo Direito de Ensinar e de Aprender e a criação dos Pontos ou Polos educacionais (norte, sul, leste, oeste e centro) previstos na referida lei contemplava diálogos

13. As Funcionais Programáticas estabelecem os recursos decorrentes das atividades educacionais realizadas no Centro Municipal de Estudos e Projetos Educacionais Julieta Diniz (CEMEPE); no âmbito do Ensino Fundamental; da Educação de Jovens e Adultos; da Educação Infantil e da Educação Especial. (Diário Oficial do Município, nº 4203, sexta-feira, 26 de julho de 2013, p. 3) 
nos diferentes espaços onde localizavam-se as escolas. E, ainda, priorizava o reconhecimento das especificidades de cada Polo, as trocas de experiências, a criação de ambientes de colaboração, a tomada de conhecimento da existência dos equipamentos públicos e produções culturais e sua valorização.

Essas ideias impactaram os processos de gestão da educação, da produção e comunicação de conhecimentos, provocando a necessidade de espaços de discussão e decisão. Conforme consta em comunicados da Secretaria Municipal de Educação sobre espaços coletivos de discussão, a decisão foi por adotar as rodas de conversa e os mini fóruns nas unidades escolares como espaços de apresentação, discussão, elaboração, implementação e avaliação de práticas coletivas visando superar problemas vinculados à educação. Em relação às razões e objetivos dos mini fóruns, Kamimura (2017, p. 105-108) esclarece:

[...] percebe-se que existe uma cultura instalada onde as instituições atuam de forma isolada/particularizada/parcializada/ fragmentada desenvolvendo suas ações para públicos, via de regra, comuns, ou seja, o usuário da educação é, por sua vez, o mesmo usuário da assistência, da saúde e das demais instituições governamentais ou não. É neste campo que foram observadas as dificuldades que emergem cotidianamente nas/das unidades escolares materializadas em situações-problema das mais diversas formas, de variados tipos, determinações, modalidades e expressões. [...] os Minifóruns começaram a acontecer nas unidades de Educação Infantil e Ensino Fundamental do município de Uberlândia [...] desenvolvidos como ação estratégico-metodológica e instrumental da Rede Pública Municipal pelo Direito de Ensinar e de Aprender. [...] têm como finalidade criar espaços de discussão, deliberação e proposição de alternativas de ação/resolução/encaminhamentos das demandas (educacionais, de assistência social, de saúde, dentre outras). Por se tratar de encontro(s) interinstitucionais onde se discute $(m)$ temas e situações-problema que, em certa medida, se vinculam e/ou afetam grupos coletivos, os mini fóruns são pautados pela construção de espaços democráticos que se prestem à reflexão/problematização/debate/ proposição/intervenção/encaminhamento de questões importantes para a otimização de ações que envolvam todos os saberes/práticas/ vivências dos participantes.

Os mini fóruns contaram com a participação de representantes de diferentes instituições e não somente das instituições escolares. As atividades dessas instituições vinculavam-se à resolução do problema identificado pelos/as profissionais da escola, remetido para discussão e encaminhamento no referido mini fórum. Foram discutidos temas, como: comportamentos agressivos e abuso sexual contra criança e adolescente.

Das rodas de conversa, desenvolvidas nas 53 unidades escolares de ensino fundamental, participaram os/as profissionais da educação presentes nas escolas onde elas ocorriam e, frequentemente, professores/as formadores/ as do Centro Municipal de Estudos e Projetos Educacionais Julieta Diniz (CEMEPE). Os temas das rodas de conversa revelaram preocupações e demandas dos/as profissionais das escolas associados aos cumprimentos dos objetivos educacionais. Foram discutidos temas e proposições em relação à infraestrutura, como: reforma e manutenção dos prédios, aquisição e reforma de mobiliário e de equipamentos tecnológicos. E, ainda, temas relativos à formação continuada, à rotatividade e à quantidade de profissionais. Também se discutiu a necessidade de melhorar as relações interpessoais nas escolas, o aumento dos salários de docentes e administrativos, a divulgação dos projetos sobre a saúde do/a servidor/a, as orientações pedagógicas e a revisão per capita de alimentos de determinadas escolas.

As rodas de conversa evidenciavam elementos da educação popular, por exemplo: o fortalecimento e a valorização da participação 
dos/as profissionais da educação na análise dos problemas identificados nas escolas e na elaboração coletiva de posições visando superálos. E, ainda, a elaboração da política de formação continuada e em serviço, estruturada a partir da realidade concreta das unidades escolares.

Nessa perspectiva, os resultados dessas discussões foram tomados como base para as ações da Política Pública de Educação para a rede municipal de ensino de Uberlândia. Assim, a Lei no 11.444/2013, que fundamentou toda a construção dessa política, se constituiu como política pública e metodologia de gestão da educação no período 2013/2016.

\section{As implicações da aprovação da Lei $n^{\circ}$ 11.444/2013 na formação com os/as profissionais da educação}

As ideias e implicações da Lei $\mathrm{n}^{\mathrm{o}}$ 11.444/2013 e a intenção de construir a escola pública, popular, democrática e de qualidade social exigiram que fossem reconhecidas as particularidades de cada unidade escolar, as demandas formativas e as necessidades de alunos/as e profissionais da educação. Analisando registros das rodas de conversa e dos mini fóruns, verificamos que esses foram, ao mesmo tempo, espaços de identificação de demandas formativas e de formação continuada.

Por meio do diálogo, os problemas eram evidenciados, discutidos e as propostas analisadas davam visibilidade às diferentes concepções e práticas presentes nas escolas. Mas, as rodas de conversa também demandaram a organização dos Planos de Formação Continuada no CEMEPE e nas unidades escolares, com a finalidade de aprofundar, do ponto de vista teórico e prático, compreensões sobre questões ou temas ali discutidos.

Os desenhos das formações continuadas foram traçados a partir da problematização da realidade concreta dos/as alunos/as e dos/ as profissionais da educação, do fomento à criação e conexão permanente de pontos de redes internas e externas às unidades escolares e à autonomia do ser do educando (FREIRE, 1996). Dessa maneira, adotou-se a pesquisaação como eixo estruturante do ensino e da formação, colocando em disputa outras proposições de educação oposta à "educação bancária" (FREIRE, 1987). Como evidenciou a análise dos Comunicados relativos à formação continuada, à gestão em rede e aos espaços de discussão coletiva. Esses comunicados fomentavam a criação de espaços coletivos de discussão em cada unidade escolar com foco nas teorias e práticas ali presentes e seus significados para o enfrentamento dos problemas identificados pela comunidade escolar. Essa perspectiva educativa, buscada a partir da problematização da realidade dos/as educandos/as e dos/as educadores/as, como mostrou os dados da pesquisa-ação, desenvolvida por meio das rodas de conversa, construiuse na perspectiva de superar a noção de que:

Se o educador é o que sabe, se os educandos são os que nada sabem, cabe àquele dar, entregar, levar, transmitir o seu saber aos segundos. Saber que deixa de ser de "experiência feito" para ser de experiência narrada ou transmitida.

Não é de estranhar, pois, que nesta visão "bancária" da educação, os homens sejam vistos como seres da adaptação, do ajustamento. Quanto mais se exercitem os educandos no arquivamento dos depósitos que Ihes são feitos, tanto menos desenvolverão em si a consciência crítica de que resultaria a sua inserção no mundo, como transformadores dele. Como sujeitos. (FREIRE, 1987, p. 68).

O diálogo envolvendo toda a comunidade escolar, por meio das Rodas de Conversa e dos Mini Fóruns, foi realizado na rede pública municipal de ensino de Uberlândia. Isso quebrou a lógica cristalizada de que as decisões para o enfrentamento dos problemas educacionais devem ser pensadas somente pela 
gestão escolar, ou, quando muito, pela gestão municipal, por meio da política engendrada pela Secretaria Municipal de Educação. Assim, as rodas de conversa e os mini fóruns contribuíram para a superação da tomada de decisões de cima para baixo e envolveu a participação coletiva daqueles/ as que são sujeitos ativos do processo educativo. E, portanto, precisam participar das decisões político/educacionais para a construção de uma educação de qualidade e voltada para o interesse da maioria dos/ as alunos/as das escolas públicas e gratuitas.

Todavia, como revelou, também, a análise dos documentos (registros das rodas de conversa e dos mini fóruns, CEMEPE Memorial 2013-2016) não se tratava apenas de realizar um levantamento dos temas para os cursos de formação desenvolvidos pelo CEMEPE. A opção formativa perseguia o propósito de transformar as escolas e o CEMEPE em espaços de investigação colaborativos, e, principalmente, vinculados aos outros pontos das redes de construção e comunicação de conhecimentos, fomentando o movimento permanente de reflexão e elaboração de teorias e práticas favoráveis à materialização do direito de ensinar e de aprender. Assim, como consta no memorial elaborado pela equipe do CEMEPE,

Esse Centro de Estudos adota uma concepção de formação contínua permanente em serviço e em rede com os/as profissionais da educação, tendo como foco a problematização das práticas pedagógicas e seus significados para o cumprimento dos objetivos de uma educação qualificada socialmente. (UBERLÂNDIA, 2016, p.7).

Nessa perspectiva, o CEMEPE se desfez da concepção de que deveria reduzir-se a um centro de promoção de eventos. Organizouse, por meio de dez Núcleos de Estudos Interdisciplinares, um dos pontos da Rede de Formação. E vinculou-se ao cotidiano das unidades escolares, fomentando com os/ as profissionais da educação, a elaboração e o desenvolvimento dos Planos de Formação no CEMEPE, nas unidades escolares e em outros espaços formativos da cidade, reconhecendo as implicações da realidade macro que, também, constituí o espaço da escola. Uma parcela significativa dessas formações foi desenvolvida em parceria com a Universidade Federal de Uberlândia (UFU) e outras instituições de ensino superior. Conforme a análise dos documentos, ocorreu tentativa de superar o enfoque disciplinar hierarquizado dos conhecimentos, a falsa dicotomia entre currículo acadêmico e não acadêmico, a formação continuada descolada dos temas e dinâmicas das escolas e da sociedade em geral. Portanto, colocando em movimento reflexões sobre saberes e fazeres das escolas e processos de elaboração coletiva de teorias e práticas pedagógicas. Dessa maneira, a lei 11.444/2013 e os demais documentos analisados e já mencionados neste texto fomentaram a leitura e a intervenção pedagógica crítica e coletiva sobre a realidade das unidades escolares articulada com o que ocorria no entorno da escola e na sociedade em geral.

Nesse contexto, uma parcela das escolas que compunha os diferentes Polos se articulava com os demais equipamentos sociais da região onde se localizava e discutia, coletivamente, as dificuldades enfrentadas pelas unidades escolares, pensando e instituindo soluções para garantir o direito de ensinar e de aprender com qualidade social. Ao Governo Municipal, como mencionado anteriormente, cabia a responsabilidade de financiar as ações deliberadas coletivamente.

Das reuniões e discussões coletivas, ocorridas nos espaços da Rede, surgiu a proposta da construção do currículo em rede. Isso se transformou em espaço de favorecimento da autonomia, das conexões, da autoria, da construção da qualidade social da educação 
pública. Essa proposta fundamentou-se nas teorias da educação popular, articulando as dimensões relativas ao currículo em andamento, a reorientação curricular, a implementação e a avaliação dos Projetos Político/Pedagógicos com as demandas formativas face às "situaçõeslimites" enfrentadas.

Esse processo se beneficiou do conteúdo da Lei Municipal no 11.444/2013, nos seguintes termos:

Art. 2ํ A Rede pelo Direito de Aprender é uma forma de atuação conjunta de instituições capazes de agir em cooperação e de estabelecer relações pautadas na autonomia, na complementaridade, na horizontalidade e no interesse comum de contribuir para garantir o direito de cada aluno(a) à educação pública, democrática, popular e qualificada socialmente.

\section{$[\ldots]$}

Art. 4을 Rede Pública Municipal pelo Direito de Ensinar e de Aprender tem como atribuição promover as seguintes ações:

I - diagnóstico e análise: leitura e discussão sobre a realidade escolar de cada setor territorial do Município de Uberlândia, com vistas ao desenvolvimento de uma educação de qualidade e pautada em direitos humanos;

II - intervenção educativa: participação na elaboração, implantação e avaliação de programas e projetos, para melhoria do fluxo e do rendimento escolar;

III - sensibilização: estimular a participação da família nas atividades escolares;

IV - organização de informações: fomentar a construção de banco de dados para subsidiar a elaboração de políticas públicas educacionais;

V - criação de ambiência educativa: criar um ambiente de colaboração entre instituições públicas e sociedade civil organizada, tendo em vista a garantia do direito à educação em direitos humanos. (UBERLÂNDIA, 2013).

O resultado das análises dos registros das rodas de conversa evidenciou, além das demandas formativas, a necessidade de retomar documentos elaborados pelas escolas, como os Projetos Políticos Pedagógicos (PPP) e os Regimentos Escolares, por conseguinte, a reformulação de práticas pedagógicas e seus fundamentos. Por essa razão, é possível afirmar que essa opção formativa pressupôs romper com a relação linear entre teoria e prática e assumir que a formação continuada é parte constituinte dos processos dialéticos presentes no ensino e na aprendizagem, implicando nas diferentes práticas escolares e sendo implicadas por elas. A título de ilustração, vejamos o quadro abaixo, elaborado a partir dos registros das rodas de conversa e dos mini fóruns. 
Quadro 1 - Formação/práticas pedagógicas e os compromissos para 2015

\begin{tabular}{|c|c|c|}
\hline Escolas - Polos & Formação e Prática Pedagógica & Compromissos para 2015 \\
\hline $\begin{array}{l}\text { Escolas Municipais do } \\
\text { Polo Centro }\end{array}$ & $\begin{array}{l}\text { Atendimento Educacional Especializado: } \\
\text { qualificar o/a profissional regente de sala - } \\
\text { oferecer formação contínua. }\end{array}$ & $\begin{array}{l}\text { Formação Permanente aos/às } \\
\text { profissionais da educação }\end{array}$ \\
\hline $\begin{array}{l}\text { Escolas Municipais do } \\
\text { Polo Leste }\end{array}$ & $\begin{array}{l}\text { Indisciplina: materializar o Projeto Político } \\
\text { Pedagógico-PPP; realizar Rodas de Conversa } \\
\text { com alunos/as; criar momentos para trocas de } \\
\text { experiências no interior da escola. }\end{array}$ & Reelaboração do PPP \\
\hline $\begin{array}{l}\text { Escolas Municipais do } \\
\text { Polo Norte }\end{array}$ & $\begin{array}{l}\text { Formação continuada que atenda às } \\
\text { necessidades dos/as professores/as para } \\
\text { promover encontros de formação em que } \\
\text { se sintam partícipes do processo, e não } \\
\text { receptáculos de informações. Proporcionar } \\
\text { espaços/encontros/visitas in loco para troca de } \\
\text { experiências. }\end{array}$ & $\begin{array}{l}\text { Formação permanente com os/ } \\
\text { as profissionais da educação, } \\
\text { tomando como foco da } \\
\text { formação a problematização } \\
\text { das práticas pedagógicas. }\end{array}$ \\
\hline $\begin{array}{l}\text { Escolas Municipais do } \\
\text { Polo Oeste }\end{array}$ & $\begin{array}{l}\text { Realizar formação in loco, a fim de melhorar } \\
\text { a compreensão e socialização dos dados do } \\
\text { Índice de Desenvolvimento da Educação } \\
\text { Básica (IDEB). }\end{array}$ & $\begin{array}{l}\text { Formação permanente com os/ } \\
\text { as profissionais da educação, } \\
\text { problematizando as práticas } \\
\text { pedagógicas. }\end{array}$ \\
\hline $\begin{array}{l}\text { Escolas Municipais do } \\
\text { Polo Sul }\end{array}$ & $\begin{array}{l}\text { Relativo à indisciplina: criar e padronizar } \\
\text { regras de convivência para o ambiente escolar } \\
\text { e inseri-las no PPP; estudar PPP e Regimento } \\
\text { Escolar. }\end{array}$ & $\begin{array}{l}\text { Reelaboração do PPP e do } \\
\text { Regimento Escolar }\end{array}$ \\
\hline
\end{tabular}

Fonte: Dados organizados pelo Comitê Gestor da Rede, com base nos registros das Rodas de Conversa nas unidades escolares, no ano de 2015, disponível nos arquivos da SME. 
As análises dos registros dos mini fóruns e das rodas de conversa mostraram, também, que a implementação da Rede enfrentou várias dificuldades. Confrontou-se com a cultura de uma gestão pública fragmentada, hierarquizada, autoritária e, frequentemente, orientada por interesses particulares de grupos que atuavam no interior e no entorno das instituições públicas. A condição para enfrentar esse desafio foi conceber a gestão pública a partir de reflexões e ações coletivas, fruto do diálogo entre escolas, Secretaria Municipal de Educação (SME) e comunidades externas.

Esse diálogo se mostrou fundamental na construção de relações entre pessoas e instituições, pautadas na ética do bem coletivo e em uma nova cultura de gestão da educação pública democratizada. Entretanto, demandou esforços para compreender a complexidade teórica e metodológica de gestar, democraticamente, em rede, e ainda, produzir e comunicar conhecimentos em rede, alterando relações de poder e fomentando a criação de posturas e escolhas epistemológicas, didáticas, visões político-pedagógicas, requerendo outras maneiras de organizar o tempo e o espaço escolar e reorientações curriculares.

A busca do estabelecimento da gestão democrática da escola, da produção e comunicação de conhecimentos contemplou a inclusão da discussão coletiva acerca das práticas pedagógicas e seus fundamentos no cotidiano da escola, e também a discussão sobre os significados para a qualidade social da educação, não reduzindo os/as participantes da discussão aos/às profissionais da educação, transformando a escola em obra aberta, pública e coletiva, o que também não foi fácil.

Para efetivar essa política educacional exigiu-se colocar no Calendário Escolar tempo para a realização das rodas de conversa. Demandou paciência, diálogo, avanços e recuos para transformar atos da SME em atos educativos e debatidos, cotidianamente. $\mathrm{E}$, desse modo, reconhecer que o acirramento e a superação de algumas contradições são fundamentais para a construção da práxis educativa. Isso tornou público o debate sobre a política educacional fortalecendo redes e comunicando os projetos e ações que materializaram a Rede Pública Municipal Pelo Direito de Ensinar e de Aprender. A finalidade dessas ações foi tentar submeter, permanentemente, a política pública de educação à avaliação coletiva por meio de comunicação direta com as comunidades escolares e não escolares, uma vez que a mídia tradicional não publicou qualquer informação sobre as ações da Rede.

Destarte, é preciso reconhecer que a política pública de educação não basta ser anunciada e expressa em ações pontuais. As ações que a materializam devem ser incorporadas à cultura da gestão pública. É necessário fomentar processos educativos. Nesse contexto, verificou-se que nem sempre os encaminhamentos retirados das rodas de conversa foram implementados. Nesse sentido, é interessante ressaltar que concepções e proposições sobre violência na escola, presentes de forma minoritária nas Rodas, foram adotadas.

Assim, privilegiaram-se determinadas concepções e encaminhamentos: a violência está no sujeito e a eliminação da presença desse sujeito no espaço escolar possibilitaria o retorno à harmonia. Portanto, o melhor caminho seria a expulsão do/a aluno/a identificado/a como violento/a. Confrontando-se com discursos sobre a importância da participação da comunidade escolar na identificação, análise e encaminhamentos dos problemas identificados no cotidiano da escola, permaneceram, em determinados espaços escolares, traços de pouca vivência democrática.

Por conseguinte, evidenciou-se a importância de se continuar com o processo de dar oportunidade para que ocorram vivências que, a partir da avaliação coletiva e pública, favorecessem novos campos de 
concepções e práticas educativas. E, também, que se desenhassem os contornos para as mudanças pretendidas em relação à formação continuada com os/as profissionais da educação e à gestão da escola pública, local de estudo da maioria dos/as alunos/as das classes populares.

Nessa direção, a análise dos documentos evidenciou que o trabalho educativo em Rede favoreceua identificação eanálise dos problemas, a construção, o desenvolvimento e a avaliação das ações coletivas com vistas à superação das dificuldades nos processos educativos. Cada dificuldade exigia interações com determinados pontos da Rede, construindo trajetórias específicas e ligadas às dimensões da dificuldade.

Dessa forma, é possível argumentar a favor da rede interna nas unidades escolares e também da constituição de redes que contemplaram outras unidades, secretarias e superintendências do município, equipamentos sociais e instituições da sociedade civil. Essa trajetória de construção da Política Pública Educacional, orientada por indagações permanentes, implicou colocar a Rede Pública Municipal Pelo Direito de Ensinar e de Aprender em movimento e desenhar os contornos do Movimento de Reorientação Curricular. Esse movimento de reflexão permanente das práticas pedagógicas, seus fundamentos e significados para a, e na, construção da qualidade social da educação articulou ensino/pesquisa/formação de alunos/as e de profissionais da educação provocando a reescrita de textos e das rotinas escolares.

Esse processo, constituído de etapas articuladas e orientadas por indagações e intervenções pedagógicas (pesquisa, intervenção pedagógica e formação continuada, com os/ as profissionais da educação e os/as alunos/ as), ofereceu elementos para continuar a implementação de gestão pública. E, ainda, a formação continuada com os/as profissionais da educação em contextos de fomento da construção da escola pública, democrática, popular e gestada em rede.

\section{Considerações pertinentes}

No decorrer do texto, foram apresentados resultados da pesquisa e, por isso, a opção foi por enfatizar os mais recorrentes. A primeira observação refere-se ao fato de que os resultados das análises dos documentos permitiram revelar a centralidade da gestão democrática no fomento da escola pública popular. Esse tipo de gestão foi desenvolvido por meio do fomento à participação dos/ as profissionais e demais interessados/as em educação pública e gratuita, criando espaços coletivos de discussão e elaboração de ações pedagógicas. E, também, proposições sobre formação com os/as profissionais da educação como políticas públicas educacionais. A disposição para dialogar se mostrou fundamental no processo de reconhecimento do/a outro/a no fomento à autonomia e à autoria da comunidade escolar. Dessa forma, a quebra de hierarquias e a busca por superar a fragmentação da gestão pública implicou reflexão e ação sobre a produção e a comunicação de conhecimento.

A segunda observação é relativa à aproximação dos valores e diretrizes presentes no Memorial, nos Comunicados e na Lei no $11.444 / 2013$ com as proposições do campo da educação popular. A título de ilustração, foram expressões recorrentes nos referidos documentos: a) Trabalho coletivo, cooperativo e em rede; b) Relações entre participantes da Rede pautadas na autonomia, na complementaridade, na horizontalidade e no interesse comum em educação pública; c) Educação em direitos humanos; d) Educação pública, gratuita, laica, democrática, popular e qualificada socialmente.

A terceira observação é referente às contribuições das rodas de conversa. Essas rodas -realizadas nas unidades escolares da SME com vistas a repensar, coletivamente, os resultados educacionais, as práticas curriculares, 
o planejamento, os processos de avaliação e gestão da escola - ajudaram a organizar as intervenções necessárias para a melhoria da qualidade da educação e contribuíram para definir ações pedagógicas no âmbito da escola, com a participação da comunidade escolar e dos equipamentos sociais de cada Polo, sobretudo aqueles que, de alguma maneira, auxiliam na resolução dos problemas que afetam a educação e, assim, fomentam a construção da educação de qualidade, referenciada socialmente.

Por meio delas também se discutiu, refletiu e elaborou propostas para se pensar o Plano de Formação Docente nas unidades escolares; o Plano de Ação dos Profissionais, por ano de ensino (PAPAE). Consolidou, também, a REDE em Movimento, que abriu caminhos para o diálogo de modo a refletir, discutir e construir de forma coletiva e colaborativa, as ações que culminaram na reflexão sobre as práticas pedagógicas. A quarta observação aborda os movimentos de oposição em relação à referida política de educação. É necessário reafirmar que, mediante a implantação desta política educativa, formulada a partir da construção da Rede Pública Municipal pelo Direito de Ensinar e de Aprender, foram evidenciadas reações contrárias à transformação da escola em espaço público, enfatizando-se afastamento em relação à adoção do princípio da gratuidade e da democracia popular. Desse modo, tal política rompeu, pelo menos em parte, com a lógica de dispositivos de violência e dominação tão presentes na rede pública municipal de ensino de Uberlândia. Evidenciaram-se, também, movimentos espirais de elaboração de conhecimentos teóricos e práticos sobre educação com as classes populares, destacando outro tipo de gestão pública e de formação com os/as profissionais da educação.
A quinta observação possível resulta do fato de que a análise dos documentos mostrou que as temáticas mais discutidas nas rodas de conversa e nos mini fóruns nas unidades escolares da rede municipal de ensino fundamental e no CEMEPE se relacionaram com a área de desenvolvimento humano e, também, com as relações interpessoais, a formação docente, principalmente sobre educação especial, sexualidade, relação família/escola e indisciplina.

Além desse levantamento sobre demandas formativas, a SME passou a conhecer, de forma mais ampliada, a Rede Pública Municipal de Ensino. Isso se tornou possível a partir dos registros e informações disponibilizados em documentos impressos e eletrônicos de cada unidade educacional.

Assim, foi possível elaborar o Planejamento Participativo de cada unidade escolar e traçar, de forma coletiva, as ações a serem empreendidas; buscar a superação das dificuldades sinalizadas nas rodas de conversa; e avançar na reflexãoação-reflexão sobre a construção da escola pública, gratuita, popular, democrática, de qualidade referenciada socialmente e gestada em rede.

Essa última observação refere-se às limitações deste estudo, apesar de reconhecer a importância da identificação e análise de documentos para compor compreensões sobre experiências educacionais, bem como aproximações eafastamentos dessas experiências do campo da educação popular. Por conseguinte, outras pesquisas com inclusão de trabalho de campo apresentam-se como tarefa a ser realizada, de maneira a continuar perseguindo a identificação e análise de concepções, princípios e práticas de educação, buscando elementos para refletir sobre educação popular. 


\section{Referências}

BRASIL. Secretaria Geral da Presidência da República. Secretaria Nacional de Articulação Social Departamento de Educação Popular e Mobilização Cidadã. Marco de referência da educação popular para as políticas públicas 2013. Disponível em: <Http://conae2014.mec.gov.br/images/ pdf/MarcodeReferencia >. Acesso em: 2 fev. 2018.

CELLARD, A. A análise documental. In: POUPART, J. et al. A pesquisa qualitativa: enfoques epistemológicos e metodológicos. Petrópolis: Vozes, 2012. p. 295-316.

DYE, T. D. Understanding public policy. Englewood Cliffs: Prentice-Hall, 1984.

FREIRE, P. Pedagogia da Autonomia: saberes necessários à prática educativa. São Paulo: Paz e Terra, 1996. 54 p.

Pedagogia do Oprimido. Rio de Janeiro: Paz e Terra, 1987. 256 p.

GADOTTI, M. Qualidade na educação: uma nova abordagem. São Paulo: Instituto Paulo Freire, 2010. 36 p.

KAMIMURA, A. L. M. Os minifóruns enquanto experiência inovadora. In: NOVAIS, G. S.; NUNES, S. do C. (Org.). Rede pública pelo direito de ensinar e de aprender: experiências coletivas de políticas públicas. Uberlândia: Regência e Arte Editora, 2017. p. 107-126.

THIOLLENT, M. Metodologia da pesquisa-ação. São Paulo: Cortez, 2009. 132 p.

SILVA, M. A. Qualidade social da educação pública: algumas aproximações. Cadernos Cedes, Campinas, v. 29, n. 78, p. 216-226, maio/ago., 2009.

UBERLÂNDIA. Lei no 11.444, de 24 de julho de 2013. Institui a rede pública municipal pelo direito de ensinar e de aprender no município de Uberlândia e dá outras providências. Diário Oficial do Município, 26 jul. 2013. Disponível em: <http://www.uberlandia.mg.gov.br/uploads/ cms_b_arquivos/9242.pdf>. Acesso em: 24 jun. 2018.

. CEMEPE Memorial 2013-2016. Uberlândia: Prefeitura Municipal de Uberlândia, 2016. 66

p.

VYGOTSKY, L. S. A formação social da mente. Tradução de José Cipolla Neto, Luis Silveira Menna Barreto e Solange Castro Afeche. 4. ed. São Paulo: Martins Fontes, 1991. 191 p.

WANDERLEY, L. E. Educação popular: metamorfose e veredas. São Paulo: Cortez, 2010. 142 p.

Submetido em 1을 de agosto de 2018.

Aprovado em 20 de outubro de 2018. 